\title{
Octadecanal as the Male-Produced Aggregation Pheromone of the Coconut Weevil, Amerrhinus ynca (Coleoptera: Curculionidae)
}

\author{
Palmira L. dos Santos Neta, ${ }^{a}$ Carla F. Fávaro, ${ }^{\circledR a}$ Sarah O. Macedo, ${ }^{a}$ \\ José Inácio L. Moura, ${ }^{b}$ Jan E. Bello, ${ }^{c}$ Rândilla R. C. Santos ${ }^{d}$ and Paulo H. G. Zarbin ${ }^{\circledR} * d$ \\ ${ }^{a}$ Laboratório de Controle Biológico e Semioquímicos, Universidade Estadual de Santa Cruz, \\ 45662-900 Ilhéus-BA, Brazil \\ ${ }^{b}$ Estação Experimental Lemos Maia, Comissão Executiva do Plano da Lavoura Cacaueira (CEPLAC), \\ 45690-000 Una-BA, Brazil \\ 'Provivi Inc, Santa Monica, CA 90404, USA \\ ${ }^{d}$ Laboratório de Semioquímicos, Universidade Federal do Paraná, 81531-980 Curitiba-PR, Brazil
}

\begin{abstract}
The beetle Amerrhinus ynca Sahlberg, 1823 (Coleoptera: Curculionidae) causes damage to several species of the Arecaceae family. The larvae of this palm weevil damage palm trees by causing perforations in the leaf rachis, obstructing the flow of nutrients to the plant. To date, are no registered insecticides for the control of A. ynca. An efficient control strategy would be the use of synthetic pheromones of this beetle for integrated pest management tactics. In this work, the aggregation pheromone of $A$. ynca was identified from adults collected as larvae and pupae from the rachis of coconut palm. The volatile compounds produced by A. ynca were collected via headspace aeration of adult beetles, and the identification of the pheromone was performed with gas chromatography coupled to mass spectrometry (GC-MS), GC-Fourier transform infrared spectroscopy (GC-FTIR) and GC-electroantenographic detector (GC-EAD). Dual-choice olfactometry experiments were performed to evaluate the bioactivity of the synthetic pheromone. GC analyses showed the presence of a male-specific compound that was identified as octadecanal. In GC-EAD analyses, synthetic octadecanal elicited responses of A. ynca female antennae. Behavioral bioassays showed attractiveness of synthetic compound for males and females, indicating octadecanal as the aggregation pheromone of A. ynca.
\end{abstract}

Keywords: rachis borer, semiochemicals, octadecanal

\section{Introduction}

Amerrhinus ynca Sahlberg, 1823 (Coleoptera: Curculionidae), popularly known as the leaf rachis borer is one of most important weevil pests of coconut palm, and can be found in host plants such as Copernicia prunifera (Miller) H.E. Moore, Elaeis guineensis Jacq., Syagrus coronata (Mart.) Becc., Acrocomia aculeata (Jacq.) Lodd. and Syagrus botryophora Mart. ${ }^{1}$ It is a native species of Brazil and its distribution is more frequent in the south of the state of Bahia and in the states of Espírito Santo, Rio de Janeiro and São Paulo. ${ }^{2}$ This beetle is diurnal and is normally found attacking adult and young plants during the hottest months of the year. The larvae of $A$. ynca

*e-mail: pzarbin@ufpr.br feed on the internal rachis tissues, developing large galleries. ${ }^{3}$ Damage caused by $A$. ynca can compromise more than $70 \%$ of the leaf crown of the plant, which affects metabolism and consequently, production. ${ }^{4}$ So far, there are no efficient methods to control this weevil. The technical recommendation is cultural control through visual inspections, as well as cutting and burning of infested plants, which results in increased production costs and has very little effect in reducing the pest population. ${ }^{4}$

The population of $A$. ynca could be controlled efficiently by using integrated pest management techniques exploiting the pheromone of this weevil. Long-distance pheromones in Curculionidae are usually male-specific aggregation pheromones, and the classes of compounds that correspond to these pheromones have usually been described as monoterpenoids and fatty acid derivatives (generally methyl 
branched alcohols, ketones, and esters). ${ }^{5}$ However, isophorone derivatives were recently described as a new structural motif of aggregation pheromones in Curculionidae. ${ }^{6}$ In this work, we report the identification and biological activity of a long chain aldehyde as the aggregation pheromone released by males of $A$. ynca, which may serve as a support for the development of techniques that could contribute to the management of this major pest of coconut crops.

\section{Experimental}

Insects

Coconut rachides containing larvae and pupae of A. ynca were collected from Estação Experimental Lemos Maia, located in the Municipality of Una, state

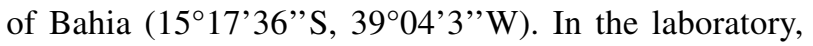
the collected rachides were kept in plastic containers $(90.0 \times 58.5 \times 5.0 \mathrm{~cm})$ lined with nylon screens, where daily observation until the emergence of adults was carried out. After emergence, the insects were collected separated by sex and transferred to plastic cages $(35.0 \times 24.5 \times 42.0 \mathrm{~cm})$ with small holes in the surface to allow airflow. Sexing was performed based on the morphology of the abdomen, following the methodology of Souza, ${ }^{7}$ where females have a rounded abdominal shape and males slightly flat. The adults were reared on fresh pieces of sugarcane and kept under ambient conditions of temperature, photoperiod and humidity $\left(27 \pm 3{ }^{\circ} \mathrm{C}, 14: 10\right.$ light:dark and $80 \%$ relative humidity). The food was replaced at intervals of 2 or 3 days, along with the cleaning of the cages.

\section{Collection of volatile compounds}

The extraction of the natural pheromone was performed by headspace aeration. The collection apparatus was maintained at the same temperature and photoperiod as the colony. Five, 10-day old beetles of each sex were separated in glass chambers containing sugar cane for feeding. A continuous flow of humidified and charcoal-filtered air generated by a vacuum pump $\left(1 \mathrm{~L} \mathrm{~min}^{-1}\right)$ was passed through the chambers carrying all volatiles to a $30 \mathrm{mg}$ adsorbent polymer (HayeSep-Q), located on glass columns connected to the chambers. Volatiles were collected for 15 days, and at each $24 \mathrm{~h}$ interval, the compounds retained in the polymer were eluted with $800 \mu \mathrm{L}$ hexane grade HPLC, and the extracts were stored in a freezer at $-20{ }^{\circ} \mathrm{C}$. Dead insects were replaced during the extraction by insects of the same age. Extracts were combined, concentrated under a gentle flow of nitrogen, and further analyzed with gas chromatography coupled to mass spectrometry (GC-MS),
GC-Fourier transform infrared spectroscopy (GC-FTIR) and GC-electroantenographic detector (GC-EAD). ${ }^{8}$

\section{Chemical analysis}

GC-MS analyses were performed with a Shimadzu QP2010-Plus with electron impact ionization (70 eV) and an RTX-5 capillary column (Restek Bellefonte, PA, USA; $30 \mathrm{~m} \times 0.25 \mathrm{~mm} \times 0.25 \mu \mathrm{m}$ film thickness). The initial analysis temperature was $50{ }^{\circ} \mathrm{C}$ for $1 \mathrm{~min}$, increasing to $7{ }^{\circ} \mathrm{C} \mathrm{min}-1$ to $250{ }^{\circ} \mathrm{C}$, and held at this temperature for $10 \mathrm{~min}$. Helium was used as carrier gas, and the injector was operated in splitless mode $\left(250^{\circ} \mathrm{C}\right)$. The temperature of the ionization source was $200{ }^{\circ} \mathrm{C}$ and the transfer line was $250{ }^{\circ} \mathrm{C}$. Mass spectral fragmentations were analyzed and compared with the National Institute of Standards and Technology (NIST) database. The retention rate was determined relative to the retention times of $\mathrm{C} 10-\mathrm{C} 26$ $n$-alkanes. Compound quantification was estimated based on the peak area relative to the octadecanal at $100 \mu \mathrm{g} \mathrm{mL}^{-1}$.

The extracts were also analyzed by GC-FTIR with a Shimadzu GC 2010 coupled to a DiscovIR infrared detector (4000-750 cm $\mathrm{cm}^{-1}, 8 \mathrm{~cm}^{-1}$ resolution; Spectra Analysis, Marlborough, MS, USA). The capillary column, injection mode, and program temperature were the same as described above.

GC-EAD analyses were obtained by a Shimadzu GC2010 chromatograph coupled to a Syntech ${ }^{\circledR}$ electroantennographic detector (Hilversum, Netherlands). The GC was equipped with an RTX-5 capillary column $(30 \mathrm{~mm} \times 0.25 \mathrm{~mm} \times 0.25 \mu \mathrm{m})$, operated in splitless mode $\left(250{ }^{\circ} \mathrm{C}\right)$, and temperature program starting at $100{ }^{\circ} \mathrm{C}$ ( $1 \mathrm{~min}$ ) and increasing $7{ }^{\circ} \mathrm{C} \mathrm{min}^{-1}$ to $250{ }^{\circ} \mathrm{C}$ (5 min). The column effluent was split in a 3:1, with one part going to the flame ionization detector (FID) $\left(270{ }^{\circ} \mathrm{C}\right)$ and three parts going through the heated transfer line into humidified airstream $\left(200 \mathrm{~mL} \mathrm{~min}^{-1}\right)$ directed to the electrodes. Insects were chilled for $5 \mathrm{~min}$ at $7{ }^{\circ} \mathrm{C}$ before each test. Due to the availability of insects, GC-EAD runs were performed only with females. The female antennae were cut off at the base and fixed between two stainless steel electrodes using conductive gel (Signa gel, Parker Labs, USA). Test solution was $1 \mu \mathrm{L}$ of the synthetic octadecanal at $100 \mu \mathrm{g} \mathrm{mL}^{-1}$. The electroantennogram was recorded in the Syntech GCEAD32 program (version 4.6).

\section{Chemical standard}

Octadecanal was synthesized by oxidation of the corresponding alcohol using pyridinium chlorochromate (PCC). ${ }^{9}$ Octadecanol and PCC were purchased from 
Acros Organics (Geel, Turnhout, Belgium). A solution of alcohol (0.50 g; $1.84 \mathrm{mmol})$ in (dichloromethane) DCM $(10.00 \mathrm{~mL})$ was added over a stirred suspension of the PCC complex $(1.20 \mathrm{~g} ; 5.56 \mathrm{mmol})$, sodium acetate $(0.095 \mathrm{~g} ; 1.15 \mathrm{mmol})$ and $1.28 \mathrm{~g}$ of celite in DCM $(15 \mathrm{~mL})$. The mixture was stirred at room temperature for $3 \mathrm{~h}$, ethyl ether $(30 \mathrm{~mL})$ was added and filtered through a Büchner funnel containing a mixture of celite and silica and the solvent was evaporated in vacuo. The octadecanal (97\%, $0.48 \mathrm{~g}$ ) was purified on the chromatographic column (9:1 hexane/ethyl acetate).

\section{Bioassays}

To verify the bioactivity of the synthetic octadecanal, an Y-shaped glass olfactometer (internal diameter $=3 \mathrm{~cm}$; length of the main tube $=35 \mathrm{~cm}$; and length of each arm $=15 \mathrm{~cm}$ ) was used. ${ }^{10}$ An insect (virgin, 10-15 days after emergence) was placed at the base of the main tube, and the sources of odors were placed at the end of each arm of the olfactometer. An airflow $\left(1.0 \mathrm{~L} \mathrm{~min}^{-1}\right)$ was generated through a vacuum pump to carry the odor from both ends of the olfactometer to the main tube. Insect's behavior was observed for $20 \mathrm{~min}$, being considered "response" when they walked against the airflow towards one of the arms of the olfactometer and remained there, and "no response" when it remained in the main tube. The treatment used was $10 \mu \mathrm{g}$ of octadecanal in hexane, that correspond to around 5 insects-equivalents, and the solvent as control. The bioassays were conducted from 10:00 am to 15:00 pm, and each insect was tested only once. To avoid the influence of luminosity on the responses and to prevent any positional affect, the olfactometer was cleaned with ethanol, dried with an air-flow for $5 \mathrm{~min}$, and the position of the arms was inverted every three tests. The odor source was replaced after each test. A total of 42 males and 28 females were tested. Insect responses were analyzed using the Chi-square test. Insects that exhibited "no response" were excluded from the statistical analysis. ${ }^{11}$ The experiments were conducted at the same temperature and photoperiod as the colony, under artificial diffuse light.

\section{Results and Discussion}

Comparison of the GC-chromatograms of volatiles collected from A. ynca males and females showed the presence of a male-specific compound with retention index of 2023 (Figure 1a). The estimated average amount of natural compound release per insect in $24 \mathrm{~h}$ was $2.16 \mu \mathrm{g}$. GC-MS, GC-FTIR analysis, as well as comparison with extracts to synthetic standards were used to elucidate the structure of the male-specific compound. The infrared spectrum (Figure 1b) showed a band at $1717 \mathrm{~cm}^{-1}$, characteristic of $\mathrm{C}=\mathrm{O}$ stretching of aldehydes. Strong $\mathrm{C}-\mathrm{H}$ stretching bands were observed around $2900 \mathrm{~cm}^{-1}$, suggesting a long-chain aliphatic aldehyde. ${ }^{12}$ The electron impact mass spectrum (EI-MS) obtained for the natural compound (Figure 1c) indicated a saturated hydrocarbon chain, and the fragment at $m / z, 250\left(\mathrm{M}^{+}-\mathrm{H}_{2} \mathrm{O}\right)$, and base peak $m / z, 82$, formed from the cyclohexene formed by McLafferty rearrangement, indicated the presence of an aldehyde functional group in the molecule. ${ }^{13}$ Fragment ions at $m / z, 43$ and 222 obtained from the first McLafferty rearrangement also confirmed the presence of an aldehyde in our isolated compound. The molecular ion, $(\mathrm{m} / \mathrm{z}, 268)$, along with the other characteristic fragments, led to the identification of the male-specific compound as octadecanal, which was further confirmed by comparison of a synthetic standard (Figure S1, Supplementary Information section).
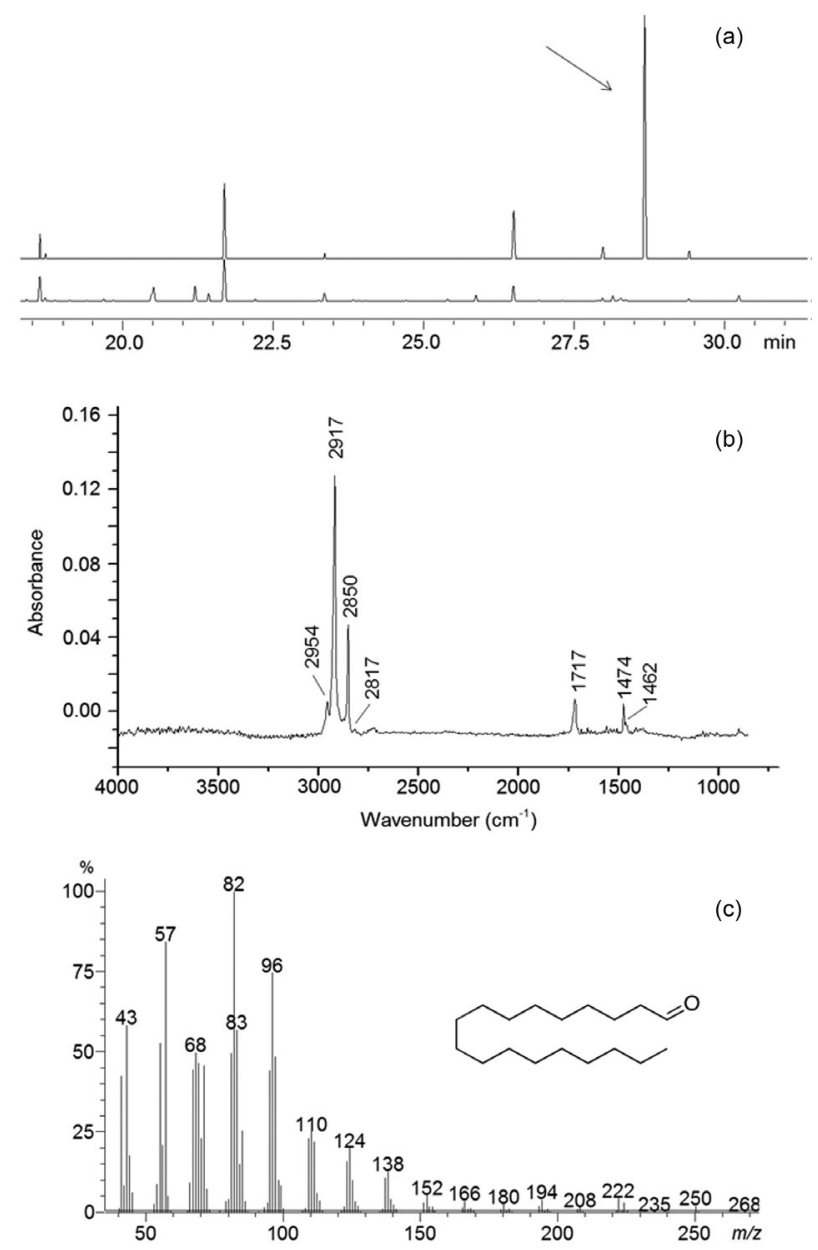

Figure 1. (a) Comparison of chromatographic profiles of volatile compounds produced by Amerrhinus ynca males (up) and females (down), the arrow indicates the male-specific compound; (b) infrared spectrum and (c) electron impact mass spectrum of the natural compound released by A. ynca males. 
Short-chain cyclic-aldehydes as the grandlures III and IV ((Z)- and (E)-2-(3,3-dimethylcyclohexylidene) acetaldehyde) and grandisal $((1 R, 2 S)$-1-methyl-2-(prop1-en-2-yl)cyclobutyl) acetaldehyde) have previously been identified as pheromone components in several Curculionidae, as occurred for Sternechus subsignatus Boheman and Pseudopiazurus obesus Boheman. ${ }^{14,15}$ On the other hand, long-chain acyclic-aldehydes have only been previously found in the cuticular extracts of one curculionid species, Oryzophagus oryzae Costa Lima. ${ }^{16}$ Three aldehydes (hexadecanal, octadecanal and eicosanal) and one ketone (nonadecane-2-one) were identified in the male and female cuticulars extracts of the $O$. oryzae beetles. However, there are no reports in the literature about longchain aldehydes identified as aggregation pheromones of Curculionidae.

The biological activity of the synthetic octadecanal was analyzed by GC-EAD and two-choice olfactometer behavioral assays using male and female A. ynca. Electroantenographic analysis (Figure 2a) showed that the octadecanal was able to elicit a small but consistent antennal response in A. ynca females. In olfactometry tests, octadecanal was significantly attractive for both males and females (Figure 2b). From 42 males tested, 33 insects chose one odor source, and $73 \%$ walked to the octadecanal $\left(\chi^{2}\right.$ Chi square value $)=21.16, \mathrm{df}$ (degree of freedom value) $=1.00, P<0.001)$. In addition, of 28 females tested, 22 insects responded to an odor source, in which $68 \%$ chose octadecanal $\left(\chi^{2}=12.96, \mathrm{df}=1.00, P<0.001\right)$. These results suggest octadecanal as being the aggregation pheromone of the species.

To date, most of pheromones identified from Curculionidae are male-specific aggregation pheromones,
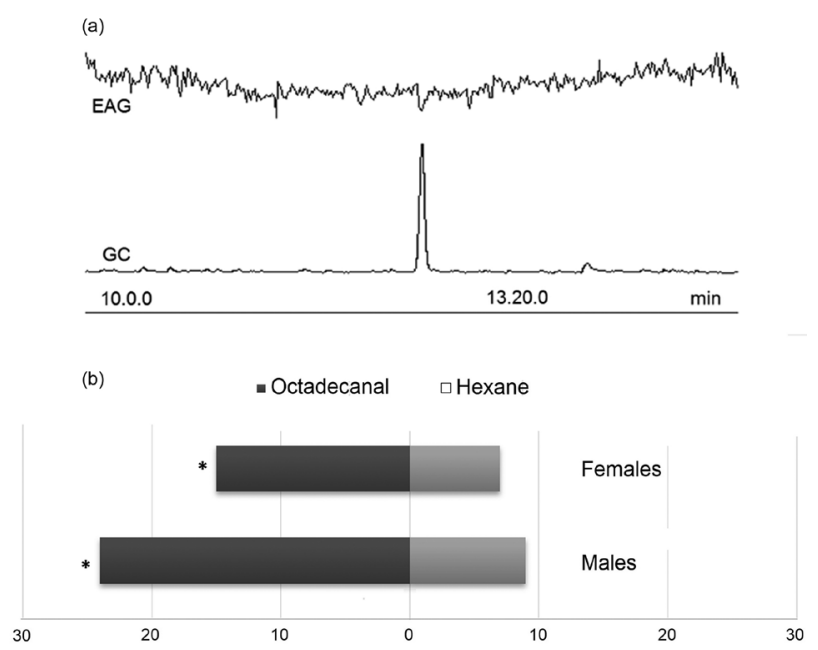

Figure 2. (a) Electroanthenogram response A. ynca female to synthetic octadecanal; (b) behavioral responses of Amerrhinus ynca males and females for octadecanal $(10 \mu \mathrm{g})$ in Y-tube olfactometer bioassays (Chisquare test, $P<0.001)$. attracting both males and females conspecifics. ${ }^{5,14}$ Among the already studied curculionid species, it is not uncommon these pheromones to be comprised of a single component. As examples, the South American palm weevil Rhynchophorus palmarum L. releases only the alcohol $(S, E)$-6-methylhept-2-en-4-ol, which induces attractive behavior to males and females of the species, ${ }^{17}$ as well as the aggregation pheromone of Sphenophorus levis Vaurie, have been identified as the alcohol $(S)$-2-methyl-4-octanol. ${ }^{18}$

\section{Conclusions}

In summary, we determined that Amerrhynus ynca produces a male-specific compound, and by using chemical analysis of volatile extracts the molecule was identified as octadecanal. Indoor bioassays employing a synthetic sample suggested the molecule as being the aggregation pheromone of the species. However, additional experiments and field evaluation are still required to confirm this hypothesis. This is the first report of a long-chain aldehyde as putative aggregation pheromone in Curculionidae. This work will contribute to the enrichment of information on the chemical ecology of insects of the Curculionidae.

\section{Supplementary Information}

Supplementary information is available free of charge at http://jbcs.sbq.org.br as PDF file.

\section{Acknowledgments}

We thank the Coordination for Improvement of Higher Education Personnel (CAPES), the State of Bahia Research Foundation (FAPESB), and the National Institute of Science and Technology (INCT) Semiochemicals in Agriculture (CNPq process 465511/2014-7 and FAPESP process 2014/50871-0) for supporting research.

\section{Author Contributions}

Palmira L. dos Santos Neta was responsible for the data curation, investigation and writing original draft; Carla F. Fávaro for the conceptualization, project administration, visualization, writing original draft, writing-review and editing; Sarah O. Macedo for the data curation and investigation; José Inácio L. Moura for the conceptualization and investigation; Jan E. Bello for the visualization, writingreview and editing; Rândilla R. C. Santos for the data curation, investigation, writing-review and editing; Paulo $\mathrm{H}$. G. Zarbin for the conceptualization, project administration, visualization, writing-review and editing. 


\section{References}

1. Ferreira, J. M. S.; Lima, M. F.; Santana, D. L. Q.; Moura, J. I. L.; Souza, L. A. In A Cultura do Coqueiro no Brasil; Ferreira, J. M. S.; Warwick, D. R. N.; Siqueira, L. A., eds.; Embrapa: Brasília, Brazil, 1997, p. 189.

2. Moura, J. I. L. In Manejo Integrado das Pragas das Palmeiras; Moura, J. I. L., ed.; CEPLAC/ESMAI: Ilhéus, Bahia, 2016, p. 57.

3. Moura, J. I. L.; Mariau, D.; Delabie, J.; Oleagineux 1994, 49, 221.

4. Ferreira, J. M. S.; Lins, P. M. P.; In Produção Integrada de Coco: Identificação de Pragas, Doenças e Desordens Nutricionais e Fisiológicas; Ferreira, J. M. S.; Fontes, H. R., eds.; Embrapa Tabuleiros Costeiros: Aracaju, Brazil, 2006, p. 11.

5. Ambrogi, B. G.; Vidal, D. M.; Zarbin, P. H. G.; Rosado-Neto, G. H.; Quim. Nova 2009, 32, 2151.

6. Vidal, D. M.; Moreira, M. A. B.; Coracini, M. D. A.; Zarbin, P. H. G.; Sci. Rep. 2019, 9, 776.

7. Souza, R. M.: Sinais Envolvidos na Comunicação de Amerrhinus ynca Sahlberg, 1823 (Coleoptera: Curculionidae); $\mathrm{PhD}$ thesis, Universidade Estadual do Norte Fluminense, Campos dos Goytacazes, Rio de Janeiro, 2006, available at https://uenf.br/posgraduacao/producao-vegetal/wp-content/ uploads/sites/10/2017/11/Rodolfo.pdf, accessed in June 2021.
8. Fávaro, C. F.; Santos, T. B.; Zarbin, P. H. G.; J. Chem. Ecol. 2012, 38, 1124.

9. Ferreira, J. T. B.; Zarbin, P. H. G.; Bioorg. Med. Chem. 1996, 4, 381 .

10. Kogel, W. J.; Koschier, E. H.; Visser, H.; Proc. Sect. Exp. Appl. Entomol. Neth. Entomol. Soc. 1999, 10, 131.

11. Baker, T. C.; Francke, W.; Millar, J. G.; Lofstedt, C.; Hansson, B.; Du, J.-W.; Phelan, P. L.; Vetter, R. S.; Youngman, R.; Todd, J. L.; J. Chem. Ecol. 1991, 17, 1973.

12. Silverstein, R. M.; Bassler, G. C.; Morrill, T. C.; Spectrometric Identification of Organic Compounds, $7^{\text {th }}$ ed.; John Wiley \& Sons: New York, NY, 2005.

13. Ogihara, S.; Am. J. Anal. Chem. 2018, 9, 46.

14. Ambrogi, B. G.; Cortés, A. M.; Zarbin, P. H. G.; J. Chem. Ecol. 2012, 38, 272.

15. Zarbin, P. H. G.; Moreira, M. A.; Haftmann, J.; Francke, W.; Oliveira, A. R.; J. Braz. Chem. Soc. 2007, 18, 1048.

16. Martins, C. B. C.; Saad, E. B.; Almeida, L. M.; Zarbin, P. H. G.; J. Insect Behav. 2013, 26, 812.

17. Rochat, D.; Malosse, C.; Lettere, M.; Ducrot, P. H.; Zagatti, P.; Renou, M.; Descoins, C.; J. Chem. Ecol. 1991, 17, 2127.

18. Baraldi, P. T.; Zarbin, P. H. G.; Vieira, P. C.; Correa, A. G.; Tetrahedron: Asymmetry 2002, 13, 621.

Submitted: February 5, 2021 Published online: June 14, 2021 